OPEN ACCESS

Edited by:

Carmelo Corsaro,

University of Messina, Italy

Reviewed by:

Khalid M. Mahrose,

Zagazig University, Egypt

Mojtaba Zaghari

University of Tehran, Iran

*Correspondence:

Shu-Geng Wu

wushugeng@caas.cn

Specialty section:

This article was submitted to

Nutrition and Food Science

Technology

a section of the journal

Frontiers in Nutrition

Received: 28 September 2021 Accepted: 05 November 2021 Published: 06 December 2021

Citation:

Qiu K, Zheng J-J, Obianwuna UE, Wang J, Zhang H-J, Qi G-H and Wu S-G (2021) Effects of Dietary

Selenium Sources on Physiological Status of Laying Hens and Production of Selenium-Enriched Eggs. Front. Nutr. 8:726770

doi: 10.3389/fnut.2021.726770

\section{Effects of Dietary Selenium Sources on Physiological Status of Laying Hens and Production of Selenium-Enriched Eggs}

\author{
Kai Qiu', Jun-Jie Zheng ${ }^{2}$, Uchechukwu Edna Obianwuna ${ }^{1}$, Jing Wang ${ }^{1}$, Hai-Jun Zhang ${ }^{1}$, \\ Guang-Hai $\mathrm{Qi}^{1}$ and Shu-Geng Wu ${ }^{1 *}$
}

${ }^{1}$ Risk Assessment Laboratory of Feed Derived Factors to Animal Product Quality Safety of Ministry of Agriculture \& Rural Affairs, National Engineering Research Center of Biological Feed, Institute of Feed Research, Chinese Academy of Agricultural Sciences, Beijing, China, ${ }^{2}$ Beijing Agricultural Products Quality and Safety Center, Beijing, China

Developing new sources of organic selenium (Se) has potential benefits for animal production and human nutrition via animal-based foods enriched with Se. The objective of this study was to evaluate the effects of Se-enriched insect protein (SEIP) in comparison with other sources, such as sodium selenite (SS) and selenium-enriched yeast (SEY), on performance, egg quality, selenium concentration in eggs, serum biochemical indices, immune capacity, and intestinal morphology of laying hens. Four hundred and fifty 24-week-old Hy-Line Brown laying hens with $94.0 \pm 1.5 \%$ laying rate were randomly allocated to five groups with six replicates of 15 hens each. The control diet was prepared without adding exogenous selenium (calculated basal Se content of $0.08 \mathrm{mg} / \mathrm{kg}$ ). The normal group was fed basal diets supplemented with $0.3 \mathrm{mg} / \mathrm{kg}$ of Se provided by sodium selenite. Three treatment groups (SS, SEY, and SEIP, respectively) were fed basal diets supplemented with $2 \mathrm{mg} / \mathrm{kg}$ of Se provided by sodium selenite, Se-enriched yeast, and SEIP, respectively. The feeding trial lasted for 12 weeks. Results revealed that dietary supplementation of $2 \mathrm{mg} / \mathrm{kg}$ of Se increased egg weight, decreased feed conversion ratio, and enhanced the antioxidant capacity of eggs in laying hens relative to the control group, whereas no significant differences were observed among SS, SEY, and SEIP treatment groups for the same. The organic source of Se provided by SEY or SEIP showed higher bio efficiency, as indicated by higher selenium content in eggs of SEY and SEIP compared with SS, although higher content was observed in SEY compared with SEIP. Also, the organic Se source significantly improved antioxidant capacity and immune functions of laying hens than the inorganic Se source. Diets supplemented with SEIP and SS significantly improved jejunal morphology of the laying hens compared with SEY, whereas SEIP was more effective than SEY to improve the oviduct health of laying hens. The results of this work evidently points the additive effect and nontoxicity of SEIP. Thus, SEIP could be used as another organic source of Se in the diet of laying hens and production of selenium-enriched eggs for humans.

Keywords: Se-enriched insect protein, antioxidant capacity, egg quality, Se-enriched eggs, laying hen 


\section{INTRODUCTION}

Selenium (Se) is an essential trace element for animal and human health and plays a key role in biological functions, such as body development and metabolism, immune function, antioxidant defense system, aging, and reproduction (1-6). Nowadays, Se as a nutritional feed additive is widely used in livestock industry to maintain health and performance via increasing the antioxidant capacity of the animals $(7,8)$. As an essential mineral element, the requirement of Se for laying hens is relatively low, about $0.3 \mathrm{mg} / \mathrm{kg}$ in diets, whereas once as an nutritional additive, its supplementation should be elevated to increase bioefficiency (9). However, Se toxicosis often appears when the concentrations are slightly increased over the level as an essential element for animals (10). Therefore, it is needed to exploit low-toxic and even nontoxic Se sources for laying hens. At present, the Se additives common used in the poultry feed include inorganic forms, such as sodium selenite and nano-Se, and organic forms, like Se-enriched yeast and Se-Met $(11,12)$.

Optimal Se supplementation in diets is not only good for the health of laying hens but also a nutritional strategy to promote high-quality egg production (13-15). For humans, dietary Se could be used to minimize clinical complications caused by prematurity (16), but the reference values of Se intake for patients with inflammation could not be usually satisfied (17). The antagonistic action of Se on heavy metals could attenuate the adverse effects of lead and cadmium on animal health (18-22). Long-term of Se supplementation gives out a potential therapeutic effect in subjects suffering from coronary artery disease (23). Se deficiency in food inhibits myocardial development and results in hypothyroidism, a weakened immune system, Ke-shan disease, and Kaschin-beck disease (4, 24, 25). Se supplementation also plays an important role in preventing the expected metabolic alterations induced by physical inactivity and sedentary behaviors in modern life (26). Therefore, it is necessary to produce Se-enriched foods for human health.

The deposition of Se in eggs of laying hens depends on the content and source of Se in diets, and organic Se from yeast or kale sprout showed great efficiency than the inorganic Se from nano-Se or sodium selenite (27-30). In order to increase the bioefficiency of Se and its safety, Se-enriched insect protein (SEIP) was exploited through two steps of biotransformation, including microbial fermentation and insect synthesis. This work was conducted to investigate the application value of SEIP in laying hens for animal health and production of egg with high nutritional value.

\section{MATERIALS AND METHODS}

\section{Se Sources, Experimental Design, and Bird Management}

Three kinds of Se sources were used in this work including sodium selenite, Se-enriched yeast, and SEIP. Se-enriched yeast, an inactivated Se-rich yeast product (Trademark: Alkosel) generated by the screened Saccharomyces cerevisiae with high Se conversion rate, was purchased from Lallemand Animal Nutrition Inc. (Montreal, Canada). Both microbial fermentation and animal biotransformation could convert inorganic Se into Se-proteins. Se conjugated to animal protein are more safe and easily digested and used by laying hens than the Se-conjugated to bacterial protein. The procedures of SEIP are described as follows. First, yeast fermentation was applied to synthesize Serich bacteria protein using wheat bran and soybean meal as the raw materials supplemented with sodium selenite. Then vegetables and wheat bran supplemented with the Se-rich yeast protein were supplied to yellow mealworm to obtain SEIP. Finally, the SEIP was dried and smashed into SEIP powder, which was determined to contain $4,480 \mathrm{mg} / \mathrm{kg}$ of Se and then used in the diet of laying hens.

Four hundred and fifty 24-week-old Hy-Line Brown laying hens with $94.0 \pm 1.5 \%$ of egg production rate were allocated into five experimental diets in a randomized complete block design with laying rate as a blocking factor. Each group contained six replicates with 15 hens per replicate. The basal diet was formulated using specially made vitamin and mineral premix without Se supplementation, and its nutrients content (Table 1), except Se, meets or exceeds the requirements of the National Research Council (NRC, 1994) and Chinese Feeding Standard of Chicken (NY/T, 33-2004). The control group (Ctrl) was fed the basal diet. The normal group (Norm) was fed the basal diet supplemented with $0.3 \mathrm{mg} / \mathrm{kg}$ of Se provided by sodium selenite to meet the requirements of Se in NRC, 1994 and NY/T, 33-2004. To produce Se-enriched eggs and increase antioxidant capacity of laying hens, three Se treatment groups (SS, SEY, and SEIP) were fed basal diets supplemented with $2 \mathrm{mg} / \mathrm{kg}$ of Se provided by sodium selenite, Se-enriched yeast, and SEIP, respectively. The content of Se in experimental diets is shown in Table 1. The similar batches of yeast protein and insect protein without Se were used among groups to balance the nutrition contents of experimental diets.

Before the 12-week trial, a 1-week adaptation period was used for gradually changing the commercial diet into experimental diets. Birds had free access to water and diets throughout the experiment and were handled in accordance to Hy-Line International Online Management Guide (Hy-Line International, 2011). During the trial, all birds were raised in three-tier cages and three birds were allotted to one cage (40 $\times 40 \times 35 \mathrm{~cm}$ ) on 16 -h of light/day with $10-20 \mathrm{Lx}$ and $14^{\circ} \mathrm{C}$ -20 room temperature. Egg number, egg weight, and mortality per replicate were recorded every day. Feed intake per replicate was recorded every week and adjusted once mortality occurs. Feed conversion ratio (FCR) was calculated as feed intake/egg weight $(\mathrm{g} / \mathrm{g})$.

\section{Sample Collection}

Ten eggs per replicate were sampled at week 6 and at the end of the trial, and distributed equally for the measurement of egg quality and for the determination of cholesterol and Se contents. At week 12, the bird with similar body weight (BW) to the average BW of the replicate was selected and fasted for $12 \mathrm{~h}$. After blood sampling from the wing vein, the birds were euthanized by intravenous use of pentobarbital sodium (100 mg/kg BW) and dissected under aseptic conditions. The serum was obtained by the centrifugation of the blood at 3,000 $\mathrm{rpm} / \mathrm{min}$ for $15 \mathrm{~min}$ 
TABLE 1 | The composition and nutrient levels of experimental diets.

\begin{tabular}{|c|c|c|c|}
\hline Ingredient & Contents, \% & Nutrients & Contents \\
\hline Corn & 62.96 & Calculated values & \\
\hline Soybean meal & 26.41 & Crude protein, \% & 16.50 \\
\hline Limestone & 8.80 & Calcium, \% & 3.31 \\
\hline Dicalcium phosphate & 1.00 & Total phosphorus, \% & 0.54 \\
\hline Salt & 0.30 & Available phosphorus, \% & 0.33 \\
\hline Premix ${ }^{a}$ & 0.53 & AME, MJ/kg & 11.29 \\
\hline Total & 100.00 & Lysine, \% & 0.86 \\
\hline Selenium & Contents, mg/kg & Methionine, \% & 0.37 \\
\hline Ctrl & $0.08(0.07)$ & Met+Cys, \% & 0.65 \\
\hline Norm & $0.38(0.33)$ & Analyzed values, \% & \\
\hline SS & $2.08(1.83)$ & Crude protein, & 16.68 \\
\hline SEY & $2.08(1.87)$ & Calcium & 3.37 \\
\hline SEIP & $2.08(1.80)$ & Total phosphorus & 0.58 \\
\hline
\end{tabular}

a Vitamin and mineral premix provided the following per $\mathrm{kg}$ of diets: $V A, 12,500 \mathrm{U}$; $V D_{3}$,

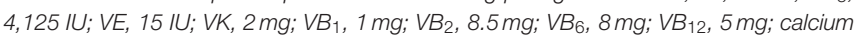
pantothenate, $50 \mathrm{mg}$; niacin, $32.5 \mathrm{mg}$; biotin, $2 \mathrm{mg}$; folic acid, $5 \mathrm{mg}$; choline, $500 \mathrm{mg}$; $\mathrm{Mn}$, $65 \mathrm{mg} ; \mathrm{l}, 1 \mathrm{mg}$; Fe, $60 \mathrm{mg}$; $\mathrm{Cu}, 8 \mathrm{mg} ; \mathrm{Zn}, 66 \mathrm{mg}$.

${ }^{b} \mathrm{Ctrl}$, the birds fed the basal diet; Norm, the birds fed $0.3 \mathrm{mg} / \mathrm{kg}$ of Se provided by sodium selenite; SS, SEY, and SEIP, the birds fed $2 \mathrm{mg} / \mathrm{kg}$ of Se provided by sodium selenite, Se yeast, and Se-enriched insect protein powder, respectively. The values out of parentheses are calculated values, and those in parentheses are analyzed values.

at $4^{\circ} \mathrm{C}$ and kept at $-20^{\circ} \mathrm{C}$ until analysis. The organs or tissues were weighed including liver, heart, spleen, duodenum, jejunum, ileum, whole small intestine, oviduct, and magnum, and the value was used to calculate the relative weight of the organ or tissue to BW. After straightened, the length of the duodenum, jejunum, ileum, the whole small intestine, oviduct, and magnum were measured using a ruler. Part of jejunum was cut off gently $(3 \mathrm{~cm})$ and immediately fixed using $10 \%$ formalin. About $1 \mathrm{~g}$ oviduct tissues was sampled, homogenized in ice-bath with $2 \mathrm{~mL}$ PBS, and then centrifuged at $4{ }^{\circ} \mathrm{C}$ and $12,000 \mathrm{rpm}$ for $10 \mathrm{~min}$ to obtain the supernatant for ELISA analysis.

\section{Egg Quality Determination}

The components of egg including albumen, yolk, and shell were separated and weighed for calculating their relative weight to the whole egg weight. Three points on the eggs were selected, including the air cell, equator, and sharp end, for the measurement of eggshell thickness using an Eggshell Thickness Gauge (ESTG1, Orka Technology Ltd., Ramat Hasharon, Israel). Eggshell-breaking strength was measured using an egg force reader (Orka Technology Ltd., Ramat Hasharon, Israel). An egg analyzer (Orka Technology Ltd., Ramat Hasharon, Israel) was used for the determination of albumen height, Haugh unit, and yolk color.

\section{Histology and Morphometric Analysis of Intestine}

According to our previous report (31), intestinal villus height $(\mathrm{VH})$ and crypt depth (CD) were measured by making paraffin sections of jejunum and staining with hematoxylin and eosin. The stained sections were photographed and analyzed at $40 \times$ magnification by a microscope coupled with a digital imaging analysis system (Nikon Eclipse 80i, Nikon Co., Tokyo, Japan). For each sample, five vertically crosscutting sections were selected and 10 well-orientated villi and the corresponding crypt for one section were measured using an Image Analyzer (Lucia Software, Lucia, Za Drahou, Czechoslovakia). The VH and CD values of each sample were generated from 50 measurements. The ratio of $\mathrm{VH}$ and $\mathrm{CD}(\mathrm{V} / \mathrm{C})$ was calculated.

\section{Chemical Analysis}

All commercial kits were purchased from Nanjing Jiancheng Bioengineering Institute (Nanjing, China), and all procedures were strictly adhered to in conformation with the manufacturer's instructions. Glutamic amino transferase (ALT), aspartate amino transferase (AST), alkaline phosphatase (ALP), uric acid (UA), creatinine (CRE), and total bilirubin (TBIL) in serum was determined using the kits with catalog no. C009-2-1, C010-21, A059-2-1, C012-2-1, C011-2-1, and C019-1-1, respectively, on an automatic biochemical analyzer (Model 7020, Hitachi, Tokyo, Japan). The activities of glutathione peroxidase (GSH$\mathrm{px}$ ), superoxide dismutase (SOD), and total antioxidant capacity (T-AOC) in serum were analyzed using the kits with catalog no. A005-1-2, A001-3-2, and A015-1-2, respectively. The content of malondialdehyde (MDA) in serum and yolk was measured using the kit with catalog no A003-1-2. Contents of immunoglobulin A (IgA) and IgG in serum, and tumor necrosis factor $\alpha$ (TNF- $\alpha)$ and epidermal growth factor receptor (EGFR) in oviduct tissues were analyzed by the ELISA method using the kits with catalog no. H108, H106, H052, and H032, respectively.

According to the cholesterol (CHO) determination method (GB/T9695.24-2008) published by Standardization Administration of China, CHO content in yolk was analyzed using gas chromatography (TRACE 1300, Thermo Fisher Scientific, Rockford, IL, USA) together with an internal standard, $5 \alpha$-CHO (Sigma-Aldrich, Inc., Saint Louis, MO, USA). In terms of the China National Standard (GB 5009.93-2017), the Se contents in experimental diets, whole egg, albumen, and yolk were analyzed using hydride-atomic fluorescence spectrometry (iCE 3300 AAS, Thermo Fisher Scientific, Rockford, IL, USA) coupled with a standard reference of Se (GBW8551, National Sharing Platform for Reference Materials, China).

\section{Statistical Analysis}

All data were analyzed by one-way ANOVA procedure of SAS 9.2 (SAS Inst. Inc., Cary, NC, USA) for a completely randomized design. The value $p \leq 0.05$ was set as the threshold for significance.

\section{RESULTS}

\section{Performance and Egg Quality}

The performance indices of laying hens are shown in Table 2. The egg production during week $1-2,3-4,5-6,7-8,9-10,11-12$, and $1-12$ was not influenced by the dietary treatments. The ADFI of laying hens in SEIP was lower $(p \leq 0.05)$ than other groups during week 7-8, while that during 1-2, 3-4, 5-6, 9-10, 11-12, and 1-12 was not influenced by experimental diets. During week 
TABLE 2 | Effects of dietary Se sources on performance of laying hens.

\begin{tabular}{|c|c|c|c|c|c|c|c|}
\hline Items $^{1}$ & Ctrl & Norm & ss & SEY & SEIP & SEM & $P$-value \\
\hline \multicolumn{8}{|c|}{ Egg production, \% } \\
\hline Week 1-2 & 93.23 & 95.76 & 95.16 & 94.05 & 94.2 & 1.05 & 0.48 \\
\hline Week 3-4 & 92.78 & 94.84 & 92.06 & 90.63 & 94.29 & 1.61 & 0.37 \\
\hline Week 5-6 & 88.26 & 88.57 & 90.32 & 92.30 & 91.43 & 2.09 & 0.59 \\
\hline Week 7-8 & 91.90 & 92.70 & 95.63 & 95.87 & 94.37 & 1.38 & 0.20 \\
\hline Week 9-10 & 71.51 & 72.94 & 76.03 & 73.02 & 77.22 & 2.81 & 0.59 \\
\hline Week 11-12 & 89.37 & 91.43 & 90.16 & 91.11 & 92.22 & 1.93 & 0.85 \\
\hline Week 1-12 & 88.88 & 90.44 & 90.95 & 90.54 & 91.67 & 0.92 & 0.32 \\
\hline \multicolumn{8}{|l|}{ ADFI, g } \\
\hline Week 1-2 & 117.81 & 117.93 & 117.26 & 116.17 & 114.92 & 1.18 & 0.35 \\
\hline Week 3-4 & 109.36 & 109.03 & 108.37 & 109.73 & 109.22 & 1.15 & 0.94 \\
\hline Week 5-6 & 113.40 & 113.90 & 114.79 & 113.77 & 114.06 & 0.78 & 0.79 \\
\hline Week 7-8 & $116.19^{a b}$ & $116.82^{a}$ & $117.99^{a}$ & $117.79^{a}$ & $113.43^{b}$ & 1.05 & 0.04 \\
\hline Week 9-10 & 116.47 & 116.78 & 118.62 & 118.56 & 118.17 & 0.97 & 0.38 \\
\hline Week 11-12 & 118.03 & 118.04 & 117.18 & 118.90 & 118.31 & 1.23 & 0.90 \\
\hline Week 1-12 & 116.52 & 116.73 & 117.00 & 117.11 & 115.96 & 0.54 & 0.60 \\
\hline \multicolumn{8}{|l|}{ FCR, g/g } \\
\hline Week 1-2 & $2.19^{a}$ & $2.14^{\mathrm{ab}}$ & $2.07^{\mathrm{bc}}$ & $2.11^{\mathrm{bc}}$ & $2.05^{c}$ & 0.03 & 0.02 \\
\hline Week 3-4 & 2.01 & 1.97 & 2.01 & 2.04 & 1.96 & 0.04 & 0.55 \\
\hline Week 5-6 & 2.16 & 2.18 & 2.16 & 2.12 & 2.11 & 0.06 & 0.88 \\
\hline Week 7-8 & 2.09 & 2.11 & 2.07 & 2.08 & 2.01 & 0.04 & 0.43 \\
\hline Week 9-10 & 2.757 & 2.687 & 2.601 & 2.678 & 2.568 & 0.10 & 0.72 \\
\hline Week 11-12 & 2.179 & 2.127 & 2.135 & 2.124 & 2.114 & 0.04 & 0.77 \\
\hline Week 1-12 & 2.20 & 2.18 & 2.16 & 2.17 & 2.12 & 0.02 & 0.14 \\
\hline \multicolumn{8}{|l|}{ Egg weight, g } \\
\hline Week 1-2 & 58.24 & 57.62 & 58.21 & 58.57 & 58.8 & 0.47 & 0.49 \\
\hline Week 3-4 & $58.88^{b}$ & $58.55^{b}$ & $58.46^{b}$ & $59.87^{a}$ & $59.01^{\mathrm{ab}}$ & 0.31 & 0.03 \\
\hline Week 5-6 & $59.90^{a}$ & $59.01^{a b}$ & $58.95^{b}$ & $58.27^{b}$ & $59.12^{\mathrm{ab}}$ & 0.32 & 0.03 \\
\hline Week 7-8 & 60.40 & 59.75 & 59.59 & 59.14 & 59.85 & 0.38 & 0.25 \\
\hline Week 9-10 & $59.73^{b}$ & $60.00^{b}$ & $60.39^{a b}$ & $60.95^{a}$ & $59.74^{b}$ & 0.30 & 0.04 \\
\hline Week 11-12 & 60.71 & 60.82 & 60.93 & 61.51 & 60.77 & 0.28 & 0.27 \\
\hline Week 1-12 & 59.61 & 59.23 & 59.37 & 59.65 & 59.53 & 0.22 & 0.64 \\
\hline
\end{tabular}

$a, b, c$ Means within a row with no common superscripts differ significantly $(p<0.05)$.

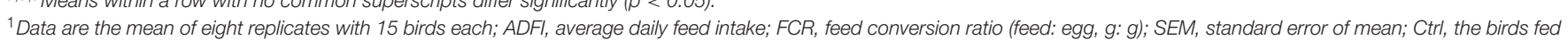

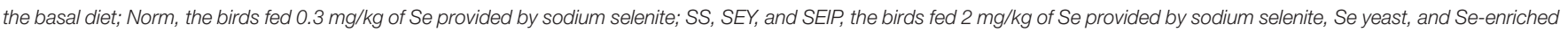
insect protein powder, respectively.

$1-2$, the laying hens in SS, SEY, and SEIP showed lower $(p \leq$ $0.05)$ FCR than those in control group, and the FCR of laying hens in SEIP was even smaller than those in Norm, whereas no differences were observed among the groups for FCR during week 3-4, 5-6, 7-8, 9-10, 11-12, and 1-12. The egg weight of laying hens in SEY was greater $(p \leq 0.05)$ than those in Ctrl, Norm, and SS during week 3-4. The laying hens in SS and SEY showed smaller $(p \leq 0.05)$ egg weight than those in Ctrl during week 5-6. The egg weight of laying hens in SEY was greatest ( $p \leq 0.05$ ) among the groups during week 9-10. There were no differences among the groups for egg weight during week 1-2, $7-8,11-12$, and $1-12$.

At week 6 and 12, no differences were observed among the experimental groups for egg quality including albumen ratio, yolk ratio, shell ratio, egg shape, shell thickness, shell stiffness, shell strength, albumen height, yolk color, and haugh units (Table 3). As shown in Table 4, the Se content of the whole egg at week 6 was significantly $(p \leq 0.05)$ high with the following trend SEY $>$ SEIP $>$ SS $>$ Norm $>$ Control. At week 6 , laying hens in SEY and SEIP showed lower $(p \leq 0.05) \mathrm{CHO}$ content in yolk than those in Ctrl, and SEIP was also lower $(P \leq 0.05)$ than Norm and SS. The MDA content of yolk was significantly ( $p$ $\leq 0.05$ ) decreased in turn from Ctrl, Norm, SS, SEY, to SEIP at week 6 . The Se content of whole egg, albumen, and yolk at week 12 showed the same varying trend $(p \leq 0.05)$ between experimental treatments as observed at week 6 . The effects of dietary treatments on the content of $\mathrm{CHO}$ in yolk was not kept to week 12. The MDA content of yolk in SS, SEY, and SEIP was lower $(P \leq 0.05)$ than those in SS, which is further lower $(P \leq$ 0.05) than those in Ctrl. 
TABLE 3 | Effects of dietary Se sources on egg quality of laying hens.

\begin{tabular}{|c|c|c|c|c|c|c|c|}
\hline Items $^{a}$ & Ctrl & Norm & SS & SEY & SEIP & SEM & $P$-value \\
\hline \multicolumn{8}{|l|}{ Week 6} \\
\hline Albumen ratio, \% & 64.70 & 64.90 & 64.59 & 64.91 & 64.29 & 0.28 & 0.52 \\
\hline Yolk ratio, \% & 24.48 & 24.24 & 24.58 & 24.48 & 24.92 & 0.25 & 0.45 \\
\hline Shell ratio, \% & 10.82 & 10.87 & 10.83 & 10.62 & 10.79 & 0.17 & 0.85 \\
\hline Egg shape index & 1.33 & 1.32 & 1.31 & 1.31 & 1.32 & 0.01 & 0.19 \\
\hline Shell thickness, mm & 0.455 & 0.447 & 0.448 & 0.453 & 0.453 & 0.01 & 0.90 \\
\hline Shell stiffness, N/mm & 77.16 & 78.62 & 78.43 & 79.10 & 79.00 & 0.57 & 0.15 \\
\hline Shell strength, N & 45.59 & 46.23 & 45.84 & 46.41 & 45.87 & 0.90 & 0.97 \\
\hline Albumen height, mm & 7.46 & 7.73 & 7.14 & 7.61 & 7.50 & 0.20 & 0.32 \\
\hline Yolk color & 5.58 & 5.63 & 5.53 & 5.43 & 5.43 & 0.15 & 0.84 \\
\hline Haugh units & 86.11 & 87.77 & 83.89 & 87.04 & 86.8 & 1.22 & 0.24 \\
\hline \multicolumn{8}{|l|}{ Week 12} \\
\hline Albumen ratio, \% & 64.39 & 64.82 & 64.44 & 64.88 & 64.43 & 0.39 & 0.83 \\
\hline Yolk ratio, \% & 25.33 & 24.82 & 25.25 & 24.76 & 25.36 & 0.36 & 0.64 \\
\hline Shell ratio, \% & 10.28 & 10.36 & 10.32 & 10.36 & 10.21 & 0.11 & 0.85 \\
\hline Egg shape index & 1.32 & 1.31 & 1.32 & 1.31 & 1.32 & 0.01 & 0.39 \\
\hline Shell thickness, mm & 0.455 & 0.443 & 0.442 & 0.455 & 0.455 & 0.01 & 0.40 \\
\hline Shell stiffness, N/mm & 77.81 & 75.62 & 77.45 & 78.93 & 78.61 & 1.92 & 0.77 \\
\hline Shell strength, N & 44.45 & 42.95 & 44.13 & 45.54 & 46.02 & 1.08 & 0.31 \\
\hline Albumen height, mm & 7.39 & 7.75 & 7.51 & 7.67 & 7.91 & 0.15 & 0.15 \\
\hline Yolk color & 7.13 & 7.17 & 7.27 & 7.97 & 7.17 & 0.31 & 0.30 \\
\hline Haugh units & 86.13 & 88.04 & 86.77 & 87.79 & 89.17 & 0.94 & 0.21 \\
\hline
\end{tabular}

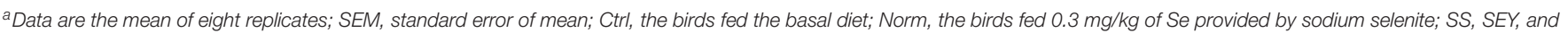
SEIP, the birds fed $2 \mathrm{mg} / \mathrm{kg}$ of Se provided by sodium selenite, Se yeast, and Se-enriched insect protein powder, respectively.

TABLE 4 | Effects of dietary Se sources on the concentration of Se, cholesterol, and malondialdehyde of eggs in laying hens.

\begin{tabular}{|c|c|c|c|c|c|c|c|}
\hline Items $^{1}$ & Ctrl & Norm & ss & SEY & SEIP & SEM & $P$-value \\
\hline \multicolumn{8}{|l|}{ Week 6} \\
\hline Egg- Se, $\mu \mathrm{g} / 100 \mathrm{~g}$ & $15.67^{e}$ & $25.67^{d}$ & $44.67^{c}$ & $115.00^{\mathrm{a}}$ & $78.50^{b}$ & 0.86 & $<0.01$ \\
\hline Yolk- $\mathrm{CHO}, \mathrm{mg} / \mathrm{g}$ & $8.04^{a}$ & $7.60^{a b}$ & $7.42^{\mathrm{ab}}$ & $7.21^{b c}$ & $6.77^{c}$ & 0.24 & 0.01 \\
\hline Yolk- MDA, nmol/mL & $88.70^{a}$ & $80.12^{b}$ & $69.24^{\mathrm{c}}$ & $72.54^{\mathrm{cd}}$ & $67.31^{d}$ & 2.09 & $<0.01$ \\
\hline \multicolumn{8}{|l|}{ Week 12} \\
\hline Egg- Se, $\mu \mathrm{g} / 100 \mathrm{~g}$ & $15.24^{e}$ & $25.34^{d}$ & $42.26^{c}$ & $116.05^{\mathrm{a}}$ & $83.20^{b}$ & 0.60 & $<0.01$ \\
\hline Albumen- Se, $\mu \mathrm{g} / 100 \mathrm{~g}$ & $5.58^{\mathrm{e}}$ & $6.92^{\mathrm{d}}$ & $17.33^{c}$ & $98.17^{\mathrm{a}}$ & $75.83^{b}$ & 0.42 & $<0.01$ \\
\hline Yolk- Se, $\mu \mathrm{g} / 100 \mathrm{~g}$ & $40.33^{e}$ & $73.17^{d}$ & $107.00^{c}$ & $162.50^{\mathrm{a}}$ & $102.33^{b}$ & 1.52 & $<0.01$ \\
\hline Yolk- $\mathrm{CHO}, \mathrm{mg} / \mathrm{g}$ & 7.87 & 7.60 & 7.35 & 6.90 & 7.25 & 0.26 & 0.13 \\
\hline Yolk- MDA, nmol/mL & $85.47^{a}$ & $80.47^{b}$ & $74.33^{\mathrm{C}}$ & $71.45^{\mathrm{C}}$ & $72.38^{c}$ & 3.09 & 0.02 \\
\hline
\end{tabular}

a,b,c Means within a row with no common superscripts differ significantly $(P<0.05)$.

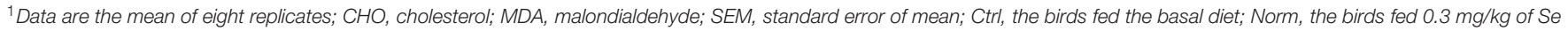
provided by sodium selenite; SS, SEY, and SEIP, the birds fed $2 \mathrm{mg} / \mathrm{kg}$ of Se provided by sodium selenite, Se yeast, and Se-enriched insect protein powder, respectively.

\section{Serum Biochemistry, Antioxidant, and Immune Capacity}

Biochemical indicators of serum of laying hens are listed in Table 5. At week 6, all biochemical indices of serum were not affected by experimental treatments including the activities of ALT, AST, and ALP, and the contents of UA, CRE, and TBIL. At week 12, the UA content in the serum of laying hens in Norm, SS, SEY, and SEIP was lower $(p \leq 0.05)$ than those in Ctrl. There were no differences between groups for the content of CRE and activities of ALT, AST, and ALP in serum. The laying hens in SEY had higher $(p \leq 0.05)$ TBIL content in serum than those in Ctrl, Norm, and SEIP. The TBIL content in serum of laying hens in SEIP was lower $(p \leq 0.05)$ than those in SS and SEY.

The antioxidant capacity and immunity of serum are shown in Table 6. At week 6, the activities of GSH-Px, SOD, and T-AOC, and the content of MDA in serum of laying hens in SEY and SEIP were higher $(p \leq 0.05)$ than those in Ctrl, Norm, and SS. The laying hens in SS had higher $(p \leq 0.05)$ activities of SOD 
TABLE 5 | Effects of dietary Se sources on blood biochemical indicators of laying hens.

\begin{tabular}{|c|c|c|c|c|c|c|c|}
\hline Items $^{1}$ & Ctrl & Norm & ss & SEY & SEIP & SEM & $P$-value \\
\hline \multicolumn{8}{|l|}{ Week 6} \\
\hline $\mathrm{ALT}, \mathrm{U} / \mathrm{L}$ & 6.81 & 6.57 & 7.04 & 6.61 & 6.93 & 0.17 & 0.27 \\
\hline AST, U/L & 125.66 & 117.21 & 115.50 & 117.28 & 118.20 & 2.60 & 0.08 \\
\hline ALP, U/L & 343.68 & 338.74 & 333.20 & 364.94 & 339.08 & 13.57 & 0.52 \\
\hline $\mathrm{UA}, \mu \mathrm{mol} / \mathrm{L}$ & 161.44 & 154.44 & 152.44 & 156.13 & 154.07 & 3.08 & 0.31 \\
\hline CRE, $\mu \mathrm{mol} / \mathrm{L}$ & 0.35 & 0.30 & 0.35 & 0.30 & 0.38 & 0.03 & 0.13 \\
\hline TBIL, $\mu \mathrm{mol} / \mathrm{L}$ & 17.94 & 17.41 & 18.19 & 17.85 & 17.78 & 0.44 & 0.80 \\
\hline \multicolumn{8}{|l|}{ Week 12} \\
\hline ALT, U/L & 6.42 & 6.65 & 6.48 & 6.61 & 6.76 & 0.20 & 0.77 \\
\hline AST, U/L & 118.35 & 119.77 & 117.90 & 117.42 & 118.69 & 0.82 & 0.34 \\
\hline ALP, U/L & 355.52 & 362.79 & 354.24 & 373.16 & 346.37 & 11.04 & 0.52 \\
\hline UA, $\mu \mathrm{mol} / \mathrm{L}$ & $160.46^{a}$ & $156.61^{b}$ & $155.08^{b}$ & $154.46^{b}$ & $154.49^{b}$ & 1.49 & 0.04 \\
\hline $\mathrm{CRE}, \mu \mathrm{mol} / \mathrm{L}$ & 0.35 & 0.35 & 0.34 & 0.35 & 0.34 & 0.01 & 0.97 \\
\hline TBIL, $\mu \mathrm{mol} / \mathrm{L}$ & $17.56^{b c}$ & $17.49^{b c}$ & $18.11^{\mathrm{ab}}$ & $18.29^{a}$ & $17.19^{c}$ & 0.25 & 0.03 \\
\hline
\end{tabular}

a,b,c Means within a row with no common superscripts differ significantly $(P<0.05)$.

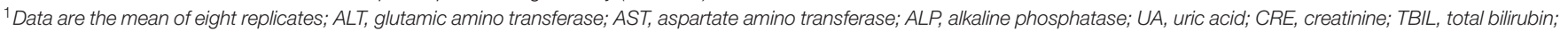

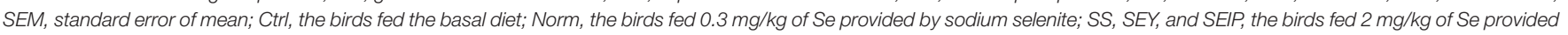
by sodium selenite, Se yeast, and Se-enriched insect protein powder, respectively.

and T-AOC, and MDA content in serum than those in Ctrl and Norm. No differences were observed between the groups for the contents of IgG and IgA in serum. At week 12, the activity of SOD in serum of laying hens was higher $(p \leq 0.05)$ in SEY and SEIP than those in Ctrl and Norm, and those in SEIP was also higher $(p \leq 0.05)$ than those in SS. The IgG content in serum of laying hens in SEY and SEIP was $(P \leq 0.05)$ higher than those in Norm. Laying hens in SEIP also had higher $(p \leq 0.05)$ IgG content in serum than those in Ctrl and SS, and the latter was higher $(p \leq$ $0.05)$ than those in the Norm. There were no differences between groups for the activities of GSH-Px and T-AOC and the content of MDA.

\section{Organ Indexes, Jejunum Morphology, and Oviduct Health}

As shown in Table 7, dietary treatments had no effects on the weight index of liver, heart, and spleen of laying hens. The weight and length indexes of intestine including duodenum, jejunum, ileum and the total small intestine were not changed by dietary treatments (Table 8). Figure 1 represents the sections of jejunum stained by HE, and the quantitative results of morphology are shown in Table 8. The jejunum morphology showed that the CD of jejunum of laying hens in SS and SEIP was shallower than those in Ctrl, Norm, and SEY. No differences existed between the groups for $\mathrm{VH}$ of jejunum. Laying hens in SS and SEIP had obvious greater $(p \leq 0.05) \mathrm{V} / \mathrm{C}$ of jejunum than those in Ctrl and Norm, and those in SEIP was also greater $(P \leq 0.05)$ than those in $S E Y$. Effects of dietary treatments on oviduct health are showed in Table 9. There were no differences between the groups for the weight and length indexes of oviduct and magnum. The oviduct tissues of laying hens in Norm, SS, and SEIP showed higher $(p \leq$ $0.05)$ protein expression of TNF- $\alpha$ than those in Ctrl, and those in SEIP was also higher $(p \leq 0.05)$ than those in SEY.

\section{DISCUSSION}

Dietary Se supplementation is critical to maintain the performance and produce Se-enriched eggs in laying hens (15). The Se sources used in the chicken feed mainly include sodium selenite, nano-Se, Se-Met, Se-Cys, and SEY $(11,12)$. Se sources with high biosafety and bioefficiency need to be continuously explored and certified in the nutrition of laying hens for the production of high quality eggs. In such perspective, SEIP was produced through two steps of biotransformation from inorganic Se; both of insects and birds are animals, whereas yeast belongs to microorganism; SEIP was hypothesized to be of lower toxicity and higher bioefficiency advantages in animal feed relative to SEY. In this work, dietary supplementation of SEIP in comparison with inorganic sources SS and SEY in laying hens diets were evaluated.

Selenium, an important component of critical amino acid complexes including Se-Met and Se-Cys, plays a key role in biological processes of laying hens. Organic forms of Se are of less toxicity and have higher bioavailability and retention in tissues compared with the inorganic forms of Se (27). In this work, dietary SS, SEY, and SEIP supplementation increased egg weight and decreased FCR of laying hens relative to the control group, and no significant differences among the dietary sources were found (SS, SEY and SEIP). This is consistent with previous reports that Se supplementation culminates in significantly enhanced egg production, egg weight, daily egg mass, and feed conversion ratio compared with the control group $(28,32)$, but varies with the results that both source and level of SS and SEY had no effects on egg weight and FCR $(29,33,34)$, and nano-Se decreased the egg production and increased the FCR (35). The variations in the studies could probably be due to different dietary levels of Se and test period 
TABLE 6 | Effects of dietary Se sources on serum antioxidant and immune capacity of laying hens.

\begin{tabular}{|c|c|c|c|c|c|c|c|}
\hline Items $^{1}$ & Ctrl & Norm & ss & SEY & SEIP & SEM & $P$-value \\
\hline \multicolumn{8}{|l|}{ Week 6} \\
\hline GSH-Px, U/mL & $744.75^{b}$ & $745.22^{b}$ & $752.80^{b}$ & $764.35^{a}$ & $766.34^{a}$ & 3.13 & $<0.01$ \\
\hline $\mathrm{SOD}, \mathrm{U} / \mathrm{mL}$ & $177.18^{\mathrm{c}}$ & $181.18^{\mathrm{C}}$ & $194.04^{b}$ & $210.52^{\mathrm{a}}$ & $217.42^{\mathrm{a}}$ & 3.44 & $<0.01$ \\
\hline T-AOC, U/mL & $9.72^{\mathrm{c}}$ & $9.61^{\mathrm{c}}$ & $10.10^{b}$ & $10.63^{a}$ & $10.55^{\mathrm{a}}$ & 0.12 & $<0.01$ \\
\hline MDA, nmol/mL & $5.49^{a}$ & $5.32^{\mathrm{a}}$ & $4.96^{b}$ & $4.62^{c}$ & $4.39^{c}$ & 0.11 & $<0.01$ \\
\hline $\operatorname{lgG}, g / L$ & 4.40 & 4.19 & 4.28 & 4.22 & 4.31 & 0.08 & 0.36 \\
\hline $\lg A, g / L$ & 2.20 & 2.08 & 2.14 & 2.10 & 2.16 & 0.05 & 0.57 \\
\hline \multicolumn{8}{|l|}{ Week 12} \\
\hline GSH-Px, U/mL & 723.75 & 728.76 & 762.49 & 758.78 & 751.55 & 21.86 & 0.63 \\
\hline $\mathrm{SOD}, \mathrm{U} / \mathrm{mL}$ & $180.01^{c}$ & $188.52^{\mathrm{c}}$ & $193.82^{b c}$ & $209.03^{a b}$ & $216.17^{a}$ & 5.61 & $<0.01$ \\
\hline T-AOC, U/mL & 9.04 & 9.67 & 11.22 & 11.05 & 10.07 & 0.61 & 0.09 \\
\hline MDA, nmol/mL & 5.06 & 5.04 & 4.92 & 4.81 & 5.34 & 0.18 & 0.30 \\
\hline lgG, g/L & $4.38^{\mathrm{bc}}$ & $4.18^{\mathrm{c}}$ & $4.69^{b}$ & $4.82^{\mathrm{ab}}$ & $5.01^{a}$ & 0.11 & $<0.01$ \\
\hline $\lg A, g / L$ & $2.01^{\mathrm{c}}$ & $2.08^{b c}$ & $2.12^{\mathrm{abc}}$ & $2.23^{\mathrm{ab}}$ & $2.24^{\mathrm{a}}$ & 0.06 & 0.04 \\
\hline
\end{tabular}

${ }_{a, b, c}$ Means within a row with no common superscripts differ significantly $(P<0.05)$.

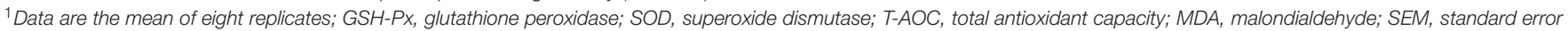

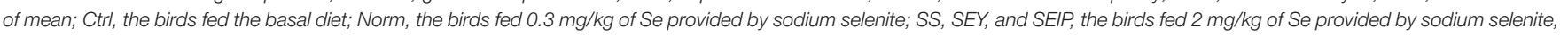
Se yeast, and Se-rich insect protein powder, respectively.

TABLE 7 | Effects of dietary Se sources on organ indexes of laying hens.

\begin{tabular}{lcccccc}
\hline Items $^{\mathrm{a}}$, \% & Ctrl & Norm & SS & SEY & SEIP & SEM \\
\hline Liver & 18.46 & 18.87 & 18.21 & 18.08 & 18.75 & 0.79 \\
Heart & 3.49 & 3.98 & 3.52 & 3.83 & 3.57 & 0.17 \\
Spleen & 1.47 & 1.43 & 1.28 & 1.23 & 1.30 & 0.15
\end{tabular}

a Data are the mean of eight replicates; The organ index was calculated as organ weight/ Live body weight. SEM, standard error of mean; Ctrl, the birds fed the basal diet; Norm,

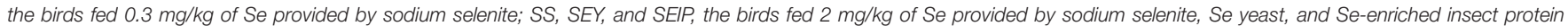
powder, respectively.

TABLE 8 | Effects of dietary Se sources on intestinal morphology of laying hens.

\begin{tabular}{|c|c|c|c|c|c|c|c|}
\hline Items $^{1}$ & Ctrl & Norm & ss & SEY & SEIP & SEM & $P$-value \\
\hline Intestine index, \%o & 33.15 & 33.28 & 34.35 & 34.32 & 31.51 & 2.09 & 0.87 \\
\hline Duodenum index, \%о & 9.56 & 8.99 & 9.30 & 9.66 & 9.50 & 0.66 & 0.95 \\
\hline Jejunum index, \%о & 13.15 & 13.45 & 14.74 & 12.89 & 11.37 & 1.06 & 0.30 \\
\hline lleum index, \%o & 9.04 & 12.53 & 10.31 & 11.76 & 9.67 & 1.06 & 0.88 \\
\hline Intestine length, mm & $1,391.67$ & $1,335.83$ & $1,340.33$ & $1,336.50$ & $1,380.33$ & 55.51 & 0.92 \\
\hline Duodenum length, mm & 120.67 & 119.83 & 125.67 & 120.67 & 119.33 & 6.90 & 0.97 \\
\hline Jejunum length, mm & 691.33 & 634.67 & 654.33 & 609.33 & 709.33 & 31.89 & 0.20 \\
\hline lleum length, mm & 579.67 & 581.33 & 560.33 & 606.50 & 551.67 & 32.33 & 0.78 \\
\hline $\mathrm{VH}, \mu \mathrm{m}$ & $1,011.34$ & $1,049.49$ & 959.77 & $1,065.56$ & $1,127.93$ & 55.19 & 0.31 \\
\hline $\mathrm{CD}, \mu \mathrm{m}$ & $197.33^{a}$ & $214.24^{a}$ & $159.06^{b}$ & $199.87^{a}$ & $165.53^{b}$ & 10.27 & $<0.01$ \\
\hline $\mathrm{V} / \mathrm{C}$ & $5.15^{\mathrm{c}}$ & $5.00^{c}$ & $6.09^{\mathrm{ab}}$ & $5.35^{\mathrm{bc}}$ & $6.84^{\mathrm{a}}$ & 0.31 & $<0.01$ \\
\hline
\end{tabular}

a,b,c Means within a row with no common superscripts differ significantly $(P<0.05)$.

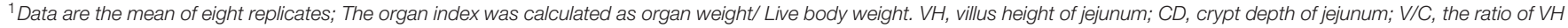

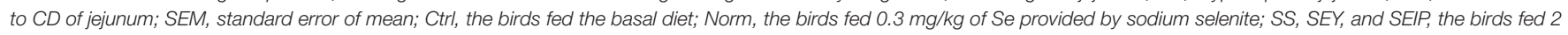
$\mathrm{mg} / \mathrm{kg}$ of Se provided by sodium selenite, Se yeast, and Se-enriched insect protein powder, respectively.

because selenoprotein expression and syntheses representing bioefficiency of Se are regulated/ governed by Se level and status in the body (9).
Previous studies have demonstrated that dietary supplementation of organic or inorganic Se had no significant effect on egg quality $(29,32-34,36)$ and the results from 


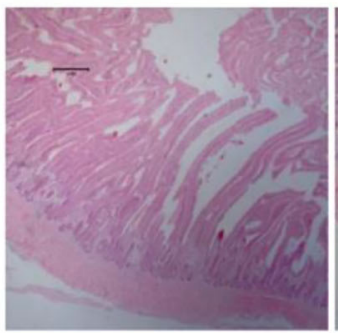

Ctrl

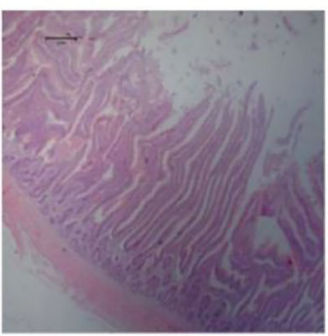

Norm

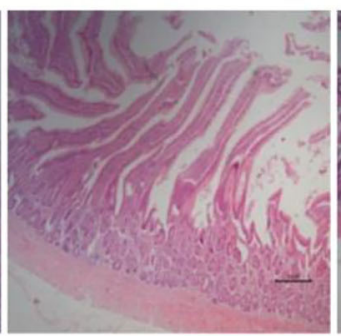

ss

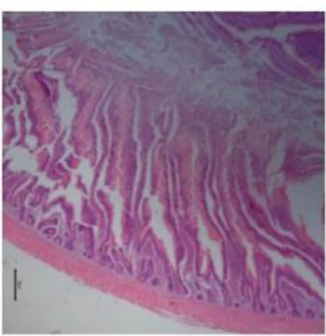

SEY

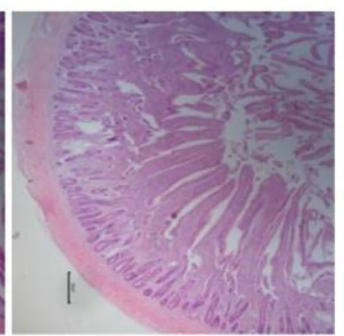

SEIP

FIGURE 1 | Effects of dietary Se sources on morphology of jejunum in laying hens. The representative pictures (40x) of jejunum section with hematoxylin and erosion (H\&E) staining. Ctrl, the birds fed the basal diet; Norm, the birds fed $0.3 \mathrm{mg} / \mathrm{kg}$ of Se provided by sodium selenite; SS, SEY, and SEIP, the birds fed $2 \mathrm{mg} / \mathrm{kg}$ of Se provided by sodium selenite, Se-enriched yeast, and Se-rich insect protein powder, respectively.

TABLE 9 | Effects of dietary Se sources on the oviduct of laying hens.

\begin{tabular}{|c|c|c|c|c|c|c|c|}
\hline Items $^{1}$ & Ctrl & Norm & SS & SEY & SEIP & SEM & $P$-value \\
\hline Oviduct index, \%о & 32.77 & 31.39 & 35.50 & 35.45 & 34.44 & 1.87 & 0.47 \\
\hline Oviduct length, mm & 575.00 & 604.67 & 649.33 & 673.00 & 614.00 & 30.60 & 0.21 \\
\hline Magnum index, \%о & 14.71 & 14.38 & 15.97 & 15.80 & 14.74 & 1.53 & 0.93 \\
\hline Magnum length, mm & 318.33 & 314.33 & 327.00 & 339.33 & 335.67 & 14.62 & 0.71 \\
\hline TNF- $\alpha, p g / m g$ & $3.04^{c}$ & $3.48^{a b}$ & $3.56^{\mathrm{ab}}$ & $3.20^{\mathrm{bc}}$ & $3.86^{a}$ & 0.14 & 0.01 \\
\hline EGFR, ng/mg & 0.69 & 0.72 & 0.73 & 0.71 & 0.77 & 0.02 & 0.25 \\
\hline
\end{tabular}

a,b,c Means within a row with no common superscripts differ significantly $(P<0.05)$.

${ }^{1}$ Data are the mean of eight replicates; The organ index was calculated as organ weight/ Live body weight. TNF- $\alpha$, tumor necrosis factor $\alpha$; EGFR, epidermal growth factor receptor;

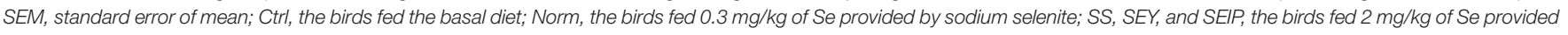
by sodium selenite, Se yeast, and Se-enriched insect protein powder, respectively.

the present study confirms same. In addition, one previous study reported that the concentration of vitamin $\mathrm{E}$ in egg yolk was increased by dietary Se supplementation (34). For the production of Se-enriched meat and eggs, Se sources are increasingly exploited as Se supplements in animal feed. The SE from organic sources have higher bioavailability value than that from inorganic sources, which is evidenced by the Se content of eggs from birds fed the said diet (32, 37-39). It was demonstrated again by the results of this work that laying hens fed SEY or SEIP showed higher Se enriched in eggs than those of SS. This study also found that the bioefficiency of SEIP was lower relative to SEY from the Se content of eggs. High $\mathrm{CHO}$ content in yolk substantially constrains the consumption of eggs owing to atherosclerotic cardiovascular risk (40). The MDA which is a by-product of oxidation tends to be high in egg yolk and as such impairs the oxidative stability of fresh eggs (41). In this work, inclusion of Se in diets significantly decreased contents of $\mathrm{CHO}$ and MDA in yolk, which are consistent with the results of previous studies about SEY $(42,43)$. Therefore, it indicated that Se supplementation in diets probably contributes to enhance shelf-life of eggs besides the production of Se-enriched eggs.

The health and physiological status of the birds are often indicated by some biochemical markers. UA, an end product of purine metabolism, is often associated with multifactorial dysfunction of the kidney (44), whereas other biomarkers such as AST, ALT, ALP, and TBIL are indicators of liver inflammation and injury (45-48). The UA content in serum of laying hens was decreased by dietary Se supplementation, which is beneficial for the kidney health. The SEIP supplementation decreased the level of TBIL in the serum relative to SS and SEY in this work, which evidently points to enhanced liver function. Also, higher TBIL content in serum of birds fed SEY diet in this work was observed, but this contradicts previous reports that Se had no significant effects on serum biochemical parameters of hens and rats $(33,49)$ and blood clinical parameters of hens (50). Such variations may be explained by the different Se sources, inclusion levels, and animals used. GSH-Px, SOD, and catalase were considered as the first line of cell antioxidant system in birds. Se is a key element in the structure of antioxidant enzymes; therefore Se supplementation may increase the GSH-Px activity $(51,52)$. Diets supplemented with SS, nano-Se, or SEY improved the antioxidant balance of laying birds by increasing GSH-Px activity $(28,42,53)$. Addition of Se in the diet improved antioxidant enzymes, CAT, and SOD in mice (54). The contents of T-AOC, T-SOD, and GSH-Px in the breast muscle of chicks were increased by Se supplementation (55). Se supplement enhanced the antioxidant system and immune function of laying hens via upregulation of GSH-Px, SOD, IgG, and IL-2 in serum $(35,56)$. This is consistent with the results of this work, where laying hens in the Se-diet groups showed high activity of antioxidants enzymes including GSH-Px, SOD, and T-AOC, low content of MDA, and high content of IgG and IgA in serum. This evidently points to 
enhanced antioxidant capacity and immune function of laying hens due to Se supplementation. The results of this work and previous works $(28,29)$ have demonstrated the bioavailability of organic Se in comparison with inorganic Se and efficacy to enhance immune and antioxidant system of laying hens. However, there are still some reports which showed that the effects of SS and SEY were approximately equal in promoting antioxidant capacity of laying hens (32), which is probably because of the low Se inclusion level in diets, $\leq 0.3 \mathrm{mg} / \mathrm{kg}$.

Nano-Se supplementation has shown to improve gut function and development of broiler chickens $(57,58)$. In this work, laying hens fed SS and SEIP showed smaller CD and greater V/C of jejunum than those in control and SEY groups, an indication that SEIP and SS enhances intestinal absorption function of laying hens in relative to SEY. TNF- $\alpha$, an inflammatory cytokine belonging to tumor necrosis factor/ tumor necrosis factor receptor (TNF/TNFR) cytokine superfamily, plays key role in biological functions, such as the maintenance of homeostatic balance and immune function, and resistance capacity to infection and cancers (59). Previous reports showed that dietary Se plays a protective role against aflatoxin $B_{1}$ and ochratoxin A-induced inflammation and apoptosis in liver and kidney (60, 61). In this work, TNF- $\alpha$ expression in oviduct tissue of laying hens was significantly higher in SEIP group compared with SEY group. Thus, an efficacy of SEIP in enhancing oviduct health has been demonstrated.

\section{CONCLUSIONS}

Diets supplemented with $2 \mathrm{mg} / \mathrm{kg}$ of inorganic or organic Se increased egg weight, decreased FCR, and enhanced the antioxidant capacity of eggs in laying hens relative to the control group, and no significant differences among the treatments SS, SEY, and SEIP was observed. The organic Se provided by SEY or SEIP showed higher bioefficiency to be deposited in eggs of laying hens relative to SS, and SEY was better than SEIP. Enhanced immune function and antioxidant capacity were associated with organic forms of Se supplementation relative to inorganic form. Diets supplemented with SEIP and SS significantly improved

\section{REFERENCES}

1. Yang Z, Liu C, Liu C, Teng X, Li S. Selenium deficiency mainly influences antioxidant selenoproteins expression in broiler immune organs. Biol Trace Elem Res. (2016) 172:209-21. doi: 10.1007/s12011-015-0578-y

2. Wan N, Xu Z, Chi Q, Hu X, Pan T, Liu T, et al. Microrna-33-3p involved in selenium deficiency-induced apoptosis via targeting adam 10 in the chicken kidney. J Cell Physiol. (2019) 234:13693-704. doi: 10.1002/jcp.28050

3. Khoso PA, Pan T, Wan N, Yang Z, Liu C, Li S. Selenium deficiency induces autophagy in immune organs of chickens. Biol Trace Elem Res. (2017) 177:159-68. doi: 10.1007/s12011-016-0860-7

4. Cai J, Yang J, Liu Q, Gong Y, Zhang Y, Zhang Z. Selenium deficiency inhibits myocardial development and differentiation by targeting the mir-215-5p/ctcf axis in chicken. Metallomics: Integrated Biometal Science. (2019) 11:415-28. doi: $10.1039 / \mathrm{c} 8 \mathrm{mt} 00319 \mathrm{j}$

5. Chi Q, Luan Y, Zhang Y, Hu X, Li S. The regulatory effects of mir-138-5p on selenium deficiency-induced chondrocyte apoptosis are mediated by targeting selm. Metallomics. (2019) 11:845-57. doi: 10.1039/c9mt00006b jejunal morphology of laying hens compared with SEY diets and SEIP significantly enhanced oviduct health relative to other diet groups. The results of this work have demonstrated the additive effect of SEIP supplementation in the production of Se-enriched eggs for humans, enhancing health and physiological status of the laying hens, and hence could be used as a feed additive of higher biosafety value than the traditional organic Se source SEY.

\section{DATA AVAILABILITY STATEMENT}

The raw data supporting the conclusions of this article will be made available by the authors, without undue reservation.

\section{ETHICS STATEMENT}

The animal study was reviewed and approved by Animal Care and Use Committee of the Feed Research Institute of the Chinese Academy of Agricultural Sciences (Approval ID: AEC-CAAS20191003).

\section{AUTHOR CONTRIBUTIONS}

S-GW, G-HQ, and H-JZ got the funding. S-GW and G-HQ conceptualized and designed the study. KQ, JW, and J-JZ performed the animal experiment. KQ, H-JZ, and UO conducted chemical analysis and analyzed the data. KQ wrote the original draft. JW, H-JZ, and UO reviewed and revised the draft. All authors agree to publish the manuscript.

\section{FUNDING}

This study was supported by Beijing Innovation Consortium of Agriculture Research System (BAIC04-2021), Shandong Key Science and Technology Innovation Program (2019JZZY010704), National Natural Science Foundation of China (32072774), and Agricultural Science and Technology Innovation Program (ASTIP) of the Chinese Academy of Agricultural Sciences.

6. Zhang Y, Wan N, Pan T, Hu X, Liu Q, Li S. Microrna-33-3p regulates vein endothelial cell apoptosis in selenium-deficient broilers by targeting e4f1. Oxid Med Cell Longev. (2019) 2019:6274010. doi: 10.1155/2019/ 6274010

7. Surai P, Fisinin V. Selenium in poultry breeder nutrition: An update. Anim Feed Sci Technol. (2014) 191:1-15. doi: 10.1016/j.anifeedsci.2014.02.005

8. Surai PF, Kochish II. Nutritional modulation of the antioxidant capacities in poultry: The case of selenium. Poult Sci. (2019) 98:4231-9. doi: $10.3382 / \mathrm{ps} /$ pey 406

9. Gladyshev VN. Eukaryotic selenoproteomes. Springer: New York (2016)

10. Ohlendorf H. Ecotoxicology of selenium. In: Hoffman DJ, Rattner BA, Burton JA, Cairns J, editors. London: CRC Press. (2003)

11. Surai PF, Fisinin VI. Selenium. Berlin/Heidelberg, Germany: Springer International Publishing. (2016)

12. Gangadoo S, Dinev I, Willson N-L, Moore RJ, Chapman J, Stanley D. Nanoparticles of selenium as high bioavailable and non-toxic supplement alternatives for broiler chickens. Environ Sci Pollut Res Int. (2020) 27:1615966. doi: 10.1007/s11356-020-07962-7 
13. Abd El-Hack ME, Mahrose K, Arif M, Chaudhry MT, Saadeldin IM, Saeed $\mathrm{M}$, et al. Alleviating the environmental heat burden on laying hens by feeding on diets enriched with certain antioxidants (vitamin e and selenium) individually or combined. Environ Sci Pollut Res Int. (2017) 24:10708-17. doi: 10.1007/s11356-017-8690-5

14. Abd El-Hack ME, Mahrose K, Askar AA, Alagawany M, Arif M, Saeed $\mathrm{M}$, et al. Single and combined impacts of vitamin a and selenium in diet on productive performance, egg quality, and some blood parameters of laying hens during hot season. Biol Trace Elem Res. (2017) 177:169-79. doi: 10.1007/s12011-016-0862-5

15. Cai SJ, Wu CX, Gong LM, Song $\mathrm{T}$, Wu H, Zhang LY. Effects of nano-selenium on performance, meat quality, immune function, oxidation resistance, and tissue selenium content in broilers. Poult Sci. (2012) 91:2532-9. doi: $10.3382 /$ ps.2012-02160

16. Freitas RGBON, Nogueira RJN, Antonio MARGM. Barros-Filho AdA, Hessel G. Selenium deficiency and the effects of supplementation on preterm infants. Rev Paul Pediatr. (2014) 32:126-35. doi: 10.1590/s0103-05822014000100019

17. Freitas RGBdON, Nogueira RJN, Cozzolino SMF, Vasques ACJ, Hessel G. Influence of selenium supplementation on patients with inflammation: A pilot double blind randomized study. Nutrition. (2017) 41:32-6. doi: 10.1016/j.nut.2017.03.007

18. Fu J, Yang T, Wang W, Xu S. Effect of selenium antagonist leadinduced damage on th1/th2 imbalance in the peripheral blood lymphocytes of chickens. Ecotoxicol Environ Saf. (2019) 175:74-82. doi: 10.1016/j.ecoenv.2019.03.036

19. Zhang R, Wang L, Zhao J, Wang C, Bao J, Li J. Effects of selenium and cadmium on ion profiles in the brains of chickens. Biol Trace Elem Res. (2016) 174:218-25. doi: 10.1007/s12011-016-0693-4

20. Chen M, Li X, Fan R, Cao C, Yao H, Xu S. Selenium antagonizes cadmium-induced apoptosis in chicken spleen but not involving nrf2regulated antioxidant response. Ecotoxicol Environ Saf. (2017) 145:503-10. doi: 10.1016/j.ecoenv.2017.08.001

21. Zhang C, Wang L-L, Cao C-Y, Li N, Talukder M, Li J-L. Selenium mitigates cadmium-induced crosstalk between autophagy and endoplasmic reticulum stress via regulating calcium homeostasis in avian leghorn male hepatoma (lmh) cells. Environ Pollut. (Barking, Essex: 1987). (2020) 265:114613. doi: 10.1016/j.envpol.2020.114613

22. Qu K-C, Li H-Q, Tang K-K, Wang Z-Y, Fan R-F. Selenium mitigates cadmium-induced adverse effects on trace elements and amino acids profiles in chicken pectoral muscles. Biol Trace Elem Res. (2020) 193:234-40. doi: 10.1007/s12011-019-01682-x

23. Gharipour M, Ouguerram K, Nazih E-H, Salehi M, Behmanesh M, Roohafza $\mathrm{H}$, et al. Effects of selenium supplementation on expression of sepp1 in mrna and protein levels in subjects with and without metabolic syndrome suffering from coronary artery disease: Selenegene study a double-blind randomized controlled trial. J Cell Biochem. (2018) 119:8282-9. doi: 10.1002/jcb.26844

24. Chen X, Yang G, Chen J, Chen X, Wen Z, Ge K. Studies on the relations of selenium and keshan disease. Biol Trace Elem Res. (1980) 2:91-107. doi: 10.1007/BF02798589

25. Combs GF. Food system-based approaches to improving micronutrient nutrition: The case for selenium. BioFactors (Oxford, England). (2000) 12:39-43. doi: 10.1002/biof.5520120107

26. Damiot A, Demangel R, Noone J, Chery I, Zahariev A, Normand S, et al. A nutrient cocktail prevents lipid metabolism alterations induced by 20 days of daily steps reduction and fructose overfeeding: Result from a randomized study. J Appl Physiol. (2019) 126:88-101. doi: 10.1152/japplphysiol.00018.2018

27. Marković R, Cirić J, Starčević M, Šefer D, Baltić MŽ. Effects of selenium source and level in diet on glutathione peroxidase activity, tissue selenium distribution, and growth performance in poultry. Anim Health Res Rev. (2018) 19:166-76. doi: 10.1017/S1466252318000105

28. Meng T, Liu Y-L, Xie C-Y, Zhang B, Huang Y-Q, Zhang Y-W, et al. Effects of different selenium sources on laying performance, egg selenium concentration, and antioxidant capacity in laying hens. Biol Trace Elem Res. (2019) 189:548-55. doi: 10.1007/s12011-018-1490-z

29. Chantiratikul A, Chinrasri O, Chantiratikul P. Effect of selenium from selenium-enriched kale sprout versus other selenium sources on productivity and selenium concentrations in egg and tissue of laying hens. Biol Trace Elem Res. (2018) 182:105-10. doi: 10.1007/s12011-017-1069-0
30. Lu J, Qu L, Shen MM, Hu YP, Guo J, Dou TC, et al. Comparison of dynamic change of egg selenium deposition after feeding sodium selenite or selenium-enriched yeast. Poult Sci. (2018) 97:3102-8. doi: 10.3382/ps/pey161

31. Qiu K, Qin CF, Luo M, Zhang X, Sun WJ, Jiao N, et al. Protein restriction with amino acid-balanced diets shrinks circulating pool size of amino acid by decreasing expression of specific transporters in the small intestine. PLoS ONE. (2016) 11:e0162475. doi: 10.1371/journal.pone.0162475

32. Han XJ, Qin P, Li WX, Ma QG Ji C, Zhang JY, et al. Effect of sodium selenite and selenium yeast on performance, egg quality, antioxidant capacity, and selenium deposition of laying hens. Poult Sci. (2017) 96:3973-80. doi: $10.3382 / \mathrm{ps} / \mathrm{pex} 216$

33. Liu H, Yu Q, Fang C, Chen S, Tang X, Ajuwon KM, et al. Effect of selenium source and level on performance, egg quality, egg selenium content, and serum biochemical parameters in laying hens. Foods. (2020) 9:68. doi: $10.3390 /$ foods 9010068

34. Tufarelli V, Cazzato E, Ceci E, Laudadio V. Selenium-fertilized tritordeum ( $\times$ tritordeum ascherson et graebner) as dietary selenium supplement in laying hens: Effects on egg quality. Biol Trace Elem Res. (2016) 173:219-24. doi: 10.1007/s12011-016-0652-0

35. Lin $\mathrm{X}$, Yang $\mathrm{T}$, Li $\mathrm{H}$, Ji Y, Zhao $\mathrm{Y}$, He J. Interactions between different selenium compounds and essential trace elements involved in the antioxidant system of laying hens. Biol Trace Elem Res. (2020) 193:252-60. doi: 10.1007/s12011-019-01701-x

36. Pavlović Z, Miletić I, Jokić Z, Pavlovski Z, Skrbić Z, Sobajić S. The effect of level and source of dietary selenium supplementation on eggshell quality. Biol Trace Elem Res. (2010) 133:197-202. doi: 10.1007/s12011-009-8422-x

37. Delezie E, Rovers M, Van der Aa A, Ruttens A, Wittocx S, Segers L. Comparing responses to different selenium sources and dosages in laying hens. Poult Sci. (2014) 93:3083-90. doi: 10.3382/ps.2014-04301

38. Utterback PL, Parsons CM, Yoon I, Butler J. Effect of supplementing selenium yeast in diets of laying hens on egg selenium content. Poult Sci. (2005) 84:1900-1.

39. Pan C, Huang K, Zhao Y, Qin S, Chen F, Hu Q. Effect of selenium source and level in hen's diet on tissue selenium deposition and egg selenium concentrations. J Agric Food Chem. (2007) 55:1027-32.

40. Puertas G, Vázquez M. Advances in techniques for reducing cholesterol in egg yolk: A review. Crit Rev Food Sci Nutr. (2019) 59:2276-86. doi: 10.1080/10408398.2018.1448357

41. An BK, Choo WD, Kang CW, Lee J, Lee KW. Effects of dietary lycopene or tomato paste on laying performance and serum lipids in laying hens and on malondialdehyde content in egg yolk upon storage. J Poult Sci. (2019) 56:52-7. doi: 10.2141 /jpsa.0170118

42. Zhang X, Tian L, Zhai S, Lin Z, Yang H, Chen J, et al. Effects of selenium-enriched yeast on performance, egg quality, antioxidant balance, and egg selenium content in laying ducks. Front Vet Sci. (2020) 7:591. doi: $10.3389 /$ fvets.2020.00591

43. Pan C, Zhao Y, Liao SF, Chen F, Qin S, Wu X, et al. Effect of selenium-enriched probiotics on laying performance, egg quality, egg selenium content, and egg glutathione peroxidase activity. J Agric Food Chem. (2011) 59:11424-31. doi: $10.1021 /$ jf202014k

44. Fathallah-Shaykh SA, Cramer MT. Uric acid and the kidney. Pediatric nephrology (Berlin, Germany). (2014) 29:999-1008. doi: $10.1007 /$ s00467-013-2549-x

45. Senior JR. Alanine aminotransferase: A clinical and regulatory tool for detecting liver injury-past, present, and future. Clin Pharmacol Ther. (2012) 92:332-9. doi: 10.1038/clpt.2012.108

46. Shim JY, Kim MH, Kim HD, Ahn JY, Yun YS, Song JY. Protective action of the immunomodulator ginsan against carbon tetrachloride-induced liver injury via control of oxidative stress and the inflammatory response. Toxicol Appl Pharmacol. (2010) 242:318-25. doi: 10.1016/j.taap.2009.11.005

47. Rinella ME. Nonalcoholic fatty liver disease: A systematic review. JAMA. (2015) 313:2263-73. doi: 10.1001/jama.2015.5370

48. Woreta TA, Alqahtani SA. Evaluation of abnormal liver tests. Med Clin North Am. (2014) 98:1-16. doi: 10.1016/j.mcna.2013.09.005

49. Konieczka P, Rozbicka-Wieczorek AJ, Czauderna M, Smulikowska S. Beneficial effects of enrichment of chicken meat with n-3 polyunsaturated fatty acids, vitamin e and selenium on health parameters: A study on male rats. Animal. (2017) 11:1412-20. doi: 10.1017/S1751731116002652 
50. Lu J, Qu L, Shen MM, Wang XG, Guo J, Hu YP, et al. Effects of high-dose selenium-enriched yeast on laying performance, egg quality, clinical blood parameters, organ development, and selenium deposition in laying hens. Poult Sci. (2019) 98:2522-30. doi: 10.3382/ps/pey597

51. Chen G, Wu J, Li C. Effect of different selenium sources on production performance and biochemical parameters of broilers. J Anim Physiol Anim Nutr. (2014) 98:747-54. doi: 10.1111/jpn.12136

52. Woods SL, Sobolewska S, Rose SP, Whiting IM, Blanchard A, Ionescu $\mathrm{C}$, et al. Effect of feeding different sources of selenium on growth performance and antioxidant status of broilers. Br Poult Sci. (2020) 61:274-80. doi: 10.1080/00071668.2020.1716301

53. Meng T-T, Lin X, Xie C-Y, He J-H, Xiang Y-K, Huang Y-Q, et al. Nanoselenium and selenium yeast have minimal differences on egg production and se deposition in laying hens. Biol Trace Elem Res. (2020) 199:2295-302. doi: 10.1007/s12011-020-02349-8

54. Abouelghar GE, El-Bermawy ZA, Salman HMS. Oxidative stress, hematological and biochemical alterations induced by sub-acute exposure to fipronil (coach) in albino mice and ameliorative effect of selenium plus vitamin e. Environ Sci Pollut Res Int. (2020) 27:7886-900. doi: 10.1007/s11356-019-06579-9

55. Yang J, Zhang M, Zhou Y. Effects of selenium-enriched bacillus sp. Compounds on growth performance, antioxidant status, and lipid parameters breast meat quality of chinese huainan partridge chicks in winter cold stress. Lipids Health Dis. (2019) 18:63. doi: 10.1186/s12944-019-1015-6

56. Sun X, Yue S-Z, Qiao Y-H, Sun Z-J, Wang C, Li H-F. Dietary supplementation with selenium-enriched earthworm powder improves antioxidative ability and immunity of laying hens. Poult Sci. (2020) 99:5344-9. doi: 10.1016/j.psj.2020.07.030

57. Gangadoo S, Dinev I, Chapman J, Hughes RJ, Van TTH, Moore RJ, et al. Selenium nanoparticles in poultry feed modify gut microbiota and increase abundance of faecalibacterium prausnitzii. Appl Microbiol Biotechnol. (2018) 102:1455-66. doi: 10.1007/s00253-017-8688-4
58. Zamani Moghaddam AK, Mehraei Hamzekolaei MH, Khajali F, Hassanpour $\mathrm{H}$. Role of selenium from different sources in prevention of pulmonary arterial hypertension syndrome in broiler chickens. Biol Trace Elem Res. (2017) 180:164-70. doi: 10.1007/s12011-017-0993-3

59. Balkwill F. Tnf-alpha in promotion and progression of cancer. Cancer Metastasis Rev. (2006) 25:409-16. doi: 10.1007/s10555-006-9005-3

60. Wu B, Mughal MJ, Fang J, Peng X. The protective role of selenium against afbinduced liver apoptosis by death receptor pathway in broilers. Biol Trace Elem Res. (2019) 191:453-63. doi: 10.1007/s12011-018-1623-4

61. Li K, Cao Z, Guo Y, Tong C, Yang S, Long M, et al. Selenium yeast alleviates ochratoxin a-induced apoptosis and oxidative stress via modulation of the pi3k/akt and nrf2/keap1 signaling pathways in the kidneys of chickens. Oxid Med Cell Longev. (2020) 2020:4048706. doi: 10.1155/2020/4048706

Conflict of Interest: The authors declare that the research was conducted in the absence of any commercial or financial relationships that could be construed as a potential conflict of interest.

Publisher's Note: All claims expressed in this article are solely those of the authors and do not necessarily represent those of their affiliated organizations, or those of the publisher, the editors and the reviewers. Any product that may be evaluated in this article, or claim that may be made by its manufacturer, is not guaranteed or endorsed by the publisher.

Copyright (C) 2021 Qiu, Zheng, Obianwuna, Wang, Zhang, Qi and Wu. This is an open-access article distributed under the terms of the Creative Commons Attribution License (CC BY). The use, distribution or reproduction in other forums is permitted, provided the original author(s) and the copyright owner(s) are credited and that the original publication in this journal is cited, in accordance with accepted academic practice. No use, distribution or reproduction is permitted which does not comply with these terms. 